\title{
Expert consensus on relevant risk predictors for the occurrence of osteoporotic fractures in specific clinical subgroups - Delphi survey
}

\author{
Nicolas S. Bodmer ${ }^{1,5^{*}}$ D, Hans Jörg Häuselmann ${ }^{2}$, Diana Frey ${ }^{3}$, Daniel Aeberli ${ }^{4}$ and Lucas M. Bachmann $n^{1,5}$
}

\begin{abstract}
Background: There is an ongoing discussion about incorporating additional risk factors to established WHO fracture risk assessment tool (FRAX) to improve the prediction accuracy in clinical subgroups. We aimed to reach an expert consensus on possible additional predictive parameters for specific clinical subgroups.

Methods: Two-round modified Delphi survey: We generated a shortlist of experts from the authors' lists of the pertinent literature and complemented the list with experts known to the authors. Participants were asked to name possible relevant risk factors besides the FRAX-parameters for the occurrence of osteoporotic fractures. Experts specified these possible predictors for specific subgroups of patients. In the second round the expert panel was asked to weight each parameter of every subgroup assigning a number between one (not important) to ten (very important). We defined the threshold for an expert consensus if the interquartile range (IQR) of a predictor was $\leq 2$. The cut-off value of the median attributed weights for a relevant predictor was set at $\geq 7$.

Results: Eleven experts of seven countries completed both rounds of the Delphi. The participants agreed on nine additional parameters for seven categories. For the category "secondary osteoporosis", "older adults" and "nursing home patients", there was a consensus that history of previous falls was relevant, while for men and postmenopausal women, there was a consensus that the spine fracture status was important. For the group "primary and secondary osteoporosis" the experts agreed on the parameters "high risk of falls", "lumbar spine bone mineral density (BMD)" and "sarcopenia".

Conclusion: This Delphi survey reached a consensus on various parameters that could be used to refine the currently existing FRAX for specific clinical situations or patient groups. The results may be useful for studies aiming at improving the predictive properties of instruments for fracture prediction.
\end{abstract}

Keywords: Primary osteoporosis, Secondary osteoporosis, Fracture prediction, Older adults, Expert consensus, Delphi consensus method

\section{Background}

Today fracture prediction is made with the well-established WHO fracture risk assessment tool (FRAX), but there is still a discussion on the completeness of the tool in terms of included parameters particularly for clinical subgroups. So far, there is no international expert consensus of fracture

\footnotetext{
* Correspondence: bodmer@medignition.ch

${ }^{1}$ Medignition Inc. Medical Research Consultants, Verena Conzett-Strasse 9 8004 Zurich, Switzerland

5University of Zurich, Rämistrasse 71, 8006 Zurich, Switzerland

Full list of author information is available at the end of the article
}

prediction parameters which impedes adequate therapy decisions. FRAX is based on individual patient models that integrate the risks associate with eleven, mostly binary, clinical risk factors and bone mineral density [1]. Incorporating additional parameters as well as adaptations of predictors are under consideration by osteoporosis experts aiming at an optimized fracture prediction. For instance, a previous unspecific fracture is classified as a risk factor by the WHO tool. This potentially includes low trauma metatarsal fracture, although it is questionable whether fractures of the hand and foot are predictors at all [2]. Additional

(c) The Author(s). 2019 Open Access This article is distributed under the terms of the Creative Commons Attribution 4.0 International License (http://creativecommons.org/licenses/by/4.0/), which permits unrestricted use, distribution, and reproduction in any medium, provided you give appropriate credit to the original author(s) and the source, provide a link to the Creative Commons license, and indicate if changes were made. The Creative Commons Public Domain Dedication waiver (http://creativecommons.org/publicdomain/zero/1.0/) applies to the data made available in this article, unless otherwise stated. 
parameters such as vitamin D-levels, falls or balance measures are under discussion for enhancing accurate fracture prediction $[2,3]$. Several researchers raised the question, whether early identification of higher fracture risk could be improved.

We aimed to reach a consensus among international experts regarding possible additional parameters besides the well-established FRAX parameters in different treatment subgroups using a two round modified Delphi.

\section{Methods}

We conducted a two-round modified online Delphi survey. The Delphi method is a systematic approach to obtain opinions of a group of experts by means of a series of short self-administered questionnaires [4].

\section{Ethics and informed consent}

No formal ethics approval was necessary for this study. Participants received a full written explanation about the scope and goals of the study. All experts participated voluntarily and provided written consent by completing the two Delphi rounds.

\section{Identification of panel members}

One researcher generated a list of potential participants of the expert consensus panel. Candidates were identified by checking the author lists of primary studies summarized in a recent systematic review [5]. Contact details of the first, second and last author of each publication were retrieved from the original publication. We complemented the list with experts known to the authors. Current e-mail addresses were verified via a general web search. Fifty experts were invited to participate. Every expert received an e-mail containing a description of the purpose of the study and an invitation to participate. Anonymous participation was granted to ensure freedom of expression. If an e-mail was rejected, we contacted the last known host institution of the expert. A reminder letter was sent out two weeks later.

\section{Survey set-up}

The questionnaire of the first round was designed by one research fellow. Following the approval from all authors the questionnaire was implemented into the survey software. The survey was conducted using the SurveyMonkey online tool [6]. The online tool allows to implement an introduction page providing information about the survey methods. Also, the system dynamically adapts its user interface offering sufficient space for the number of answers given. Moreover, it is possible to set input requirements allowing only a specific format of the answer e.g. range of the attributed weights must be a number between one and ten.

\section{First round questionnaire}

Each consenting expert received a personalized e-mail containing a description of the study method and a weblink to access the survey. Before starting to complete the questionnaire, each participant provided information about his or her specific expertise and the current affiliation. In the first round, experts were asked to name possible relevant predictors besides the well-established parameters of FRAX for the occurrence of osteoporotic fractures. They could specify these possible predictors for one or more specific subgroups of patients (e.g. patients with secondary osteoporosis).

\section{Second round questionnaire}

The feedback from the first round was extracted, examined and prepared for the second round. Obvious misspellings were corrected and plurals were replaced by singulars (e.g. fall vs. falls). Terms with the same root word were collapsed into one term if the intended meaning remained unchanged. If appropriate, a general concept was used to summarize a specific condition (i.e. kidney transplantation, lung transplantation, heart transplantation was collapsed into one term "history of transplantation"). In the questionnaire, the parameters were then grouped into the seven different subgroups. Every participant received after round one a compiled inventory of the answers. In the second round, participants weighed for each subgroup every predictor by assigning a number between one (not important) and ten (very important).

\section{Attaining a consensus on relevant parameters}

We calculated the median of the attributed weights and the corresponding interquartile ranges (IQR) for each of the parameters within each of the clinical subgroups. Using the thresholds of a previous Delphi study, we defined an expert consensus as the IQR of a predictor $\leq 2$ [7]. The cut-off value of the median attributed weights for a relevant predictor was set at $\geq 7$. Statistical analyses were performed using the Stata 14.2 statistical software package (StataCorp. 2015. Stata Statistical Software: Release 14. College Station, TX: StataCorp LP.). At the end of the Delphi study, every participant received the results of the Delphi including median and IQR of all items.

\section{Results}

Eleven experts from Australia [1], Canada [1], France [1], Israel [1], Italy [1], Norway [1], and USA [5] participated in the survey. The first round revealed thirty-six parameters for seven clinical subgroups, older adults, postmenopausal women, men, secondary osteoporosis, primary and secondary osteoporosis, nursing home patients and patients close to treatment threshold. Table 1 
Table 1 Predictors with attributed median weight and corresponding IQR

\begin{tabular}{|c|c|c|}
\hline Patient subgroups & Predictor & Median \\
\hline \multicolumn{3}{|c|}{ Secondary osteoporosis } \\
\hline & recent or multiple falls & 9 \\
\hline & aromatase inhibitors & 6.5 \\
\hline & $\begin{array}{l}\text { chronic obstructive pulmonary } \\
\text { disease }\end{array}$ & 6.5 \\
\hline & history of transplantation & 6.5 \\
\hline & $\begin{array}{l}\text { decrease in BMD over the } \\
\text { previous } 2 \text { years }\end{array}$ & 6.5 \\
\hline & $\begin{array}{l}\text { androgen deprivation therapy } \\
\text { (prostate cancer) }\end{array}$ & 6.5 \\
\hline & $\begin{array}{l}\text { rheumatic diseases other than } \\
\text { rheumatoid arthritis } \\
\text { (excluded osteoarthritis) }\end{array}$ & 6.5 \\
\hline & breast cancer therapy & 6 \\
\hline & $\begin{array}{l}\text { inflammatory activity of the } \\
\text { underlying disease }\end{array}$ & 6 \\
\hline & $\begin{array}{l}\text { severe disability form multiple } \\
\text { sclerosis or other } \\
\text { neurodegenerative conditions }\end{array}$ & 6 \\
\hline & Crohn's disease & 5.5 \\
\hline & low grip strength & 5.5 \\
\hline & gastric bypass surgery & 5.5 \\
\hline & HIV & 5 \\
\hline
\end{tabular}

Primary and secondary osteoporosis

\section{high risk of falls \\ lumbar spine BMD}

sarcopenia

dismobility syndrome

Postmenopausal women

spine fracture status
major height loss
kyphosis
early surgical menopause

Nursing home patients

falls
functional status

Men

spine fracture status

hypogonadism

Older adults

\section{falls}

functional/ambulatory status

medications (particularly psychotropic medications)

stroke

type 2 diabetes
Table 1 Predictors with attributed median weight and corresponding IQR (Continued)

\begin{tabular}{|c|c|c|c|}
\hline Patient subgroups & Predictor & Median & IQR \\
\hline & Parkinson's disease & 6 & 2.5 \\
\hline \multicolumn{4}{|c|}{ Close to treatment threshold } \\
\hline & $\begin{array}{l}\text { lumbar spine BMD } \\
\text { (for vertebral fracture } \\
\text { prediction) }\end{array}$ & 8 & 1.5 \\
\hline & type 2 diabetes & 6 & 3.5 \\
\hline & $\begin{array}{l}\text { trabecular bone score } \\
\text { (TBS) }\end{array}$ & 5.5 & 3.5 \\
\hline & $\begin{array}{l}\text { hip axis length } \\
\text { (for hip fracture prediction) }\end{array}$ & 4 & 4 \\
\hline
\end{tabular}

Predictors fulfilling the consensus criteria are marked bold

shows the attributed median weight of the thirty-six parameters and the corresponding $\mathrm{IQR}$ in descending order.

The participating experts agreed on nine additional parameters for the seven categories. The final set of predictors is shown in Table 2. For the category "secondary osteoporosis", "older adults" and "nursing home patients", there was a consensus that previous falls were relevant, while for men and postmenopausal women, there was a consensus that the spine fracture status was important. For the group "primary and secondary osteoporosis" the experts agreed on the parameters "high risk of falls", "lumbar spine bone mineral density (BMD)" and "sarcopenia". For the group close to the treatment threshold, "lumbar spine BMD" was considered relevant as a predictor for vertebral fracture prediction.

The participants of the expert panel disagreed on four parameters with a high median $(\geq 7)$ but $\mathrm{IQR}>2$. Namely the parameter "major height loss" of the subgroup "postmenopausal women", "functional status" of the subgroup "nursing home patients", "functional/ambulatory status" and "medications particularly psychotropic medications" of the subgroup "older adults".

Table 2 Consensus of relevant fracture predictors

\begin{tabular}{llll}
\hline Patient subgroups & Predictor & Median & IQR \\
\hline secondary osteoporosis & recent or multiple falls & 9 & 1 \\
primary and secondary & high risk of falls & 9.5 & 1 \\
osteoporosis & lumbar spine BMD & 7.5 & 1.5 \\
& sarcopenia & 7 & 1.5 \\
postmenopausal women & spine fracture status & 10 & 0.5 \\
nursing home patients & falls & 10 & 1.5 \\
men & spine fracture status & 10 & 0.5 \\
older adults & falls & 9.5 & 2 \\
close to treatment & lumbar spine BMD & 8 & 1.5 \\
threshold & (for vertebral fracture prediction) & \\
\hline
\end{tabular}




\section{Discussion}

\section{Main findings}

In this Delphi survey, a group of international experts agreed on additional risk parameters for osteoporotic fractures currently not covered in the WHO FRAX instrument and converged on seven different subgroups needing specific assessments. The expert consensus was highest on the predictor "recent falls" for the occurrence of osteoporotic fracture followed by spine fracture status or lumbar spine (bone mineral density (BMD)) depending on the subgroup. The parameters of clinical history "HIV", "Crohn's Disease" and the item "low grip strength" were considered less important for fracture prediction. Surprisingly, no consensus could be reached for parameters such as "functional / ambulatory status" in older adults.

\section{Results in context of the existing literature}

We are unware of any previous Delphi consensus on fracture predictors beside the established FRAX parameters. In a recent systematic review summarizing 45 studies, the authors compared thirteen fracture prediction tools and included 20 of the 45 studies in the metaanalysis grouped into three categories. In women without a BMD result available at the time point of the risk assessment, the FRAX tool was less accurate than the QFracture tool, another fracture prediction instrument published in 2009. If BMD results were available when assessing the patient, the FRAX instrument was more predictive than the QFracture tool $[8,9]$. QFracture records additional predictors such as systemic lupus erythematosus (SLE), gastrointestinal malabsorption, anticonvulsants, dementia or history of falls which indicates the need for reconsidering the set of used predictors. History of falls was also considered very relevant for the experts of the survey, while other predictors of the QFracture tool were not. The results of the Delphi Study are consistent with previous studies which identified falls in older adults as an independent predictor for the occurrence of fractures $[2,10,11]$.

The FRAX model uses a dichotomized variable for the risk factor "previous fracture" which could lead to an underestimation of fracture risk as a result of the progressively increasing risk with the number of prevalent vertebral fractures [12, 13]. Furthermore, the severity and type of fracture is pivotal for risk assessment as a prior vertebral fracture had a lower prognostic value for further non-vertebral fractures than for vertebral fracture outcomes [14].

\section{Strength and limitation}

A strength of the Delphi study is the inclusion of geographically dispersed experts and the avoidance of undue dominance by individuals through anonymity [15]. It could be argued that the small number of experts contributing to this survey limits the extent to which results can be generalized. However, this would predominately affect the first round of the Delphi and not necessarily the consensus made in round 2. Moreover, all experts had many years of experience in their field and it can be assumed that they covered the theoretical and practical aspects of osteoporosis management thoroughly. Finally, the thresholds set for relevance and consensus are somewhat arbitrary. We cannot fully rule-out that setting these thresholds differently would affect the overall message of this paper to some extent. By providing the full list of replies along with the medians and the interquartile ranges we offer readers the possibility to assess the consequences if different thresholds would have been chosen.

\section{Implications for practice and further research}

This paper presents a set of agreed parameters besides the FRAX predictors that experts considered as relevant for enhancing accurate fracture prediction. On one hand, the evaluated predictors may help clinicians in the risk assessment of the individual patient. On the other hand, we provide a basis for further discussions about possible additional fracture predictors. In an ongoing study of our research group we incorporated the parameters found in this consensus study. This will allow us to quantify improvements in the prediction when using these additional parameters in the pre-specified subgroups of patients. Further research should aim to assess the reported predictors with clinical data to confirm the importance of the items. Also, new or modified existing fracture assessment tools with additional predictors should be validated and compared with current practice. This study could guide the direction of further research and developing efforts regarding the ongoing discussion about risk factors for osteoporotic fractures.

\section{Conclusions}

In this Delphi survey, an international group of experts reached a consensus on various parameters that could be used to refine the currently existing FRAX tool for specific clinical situations or patient groups. The results may be useful for studies aiming at improving the predictive properties of instruments for fracture prediction.

\footnotetext{
Abbreviations

BMD: Bone mineral density; FRAX: WHO fracture risk assessment tool; IQR: Interquartile range; SLE: Systemic lupus erythematosus
}

Acknowledgements

Not applicable.

Authors' contributions

NSB, HJH and LMB conceived of the study. NSB and LMB compiled a long list of possible experts and discussed it with $\mathrm{HJH}$, DF and DA. NSB designed and implemented the Delphi panel and managed the Delphi process. NSB 
and $L M B$ consolidated the results of Round 1 and sought critical input from $\mathrm{HJH}, \mathrm{DF}$ and DA. All authors gave substantive input into the study results and discussion sections, and read and approved the final manuscript.

\section{Funding}

No funding was obtained for this study.

\section{Availability of data and materials}

The datasets used and/or analysed during the current study are available from the corresponding author on reasonable request.

\section{Ethics approval and consent to participate}

This project does not fall within the scope of application of the Human Research Act (HRA) and therefore no ethics approval is required. The participating experts received a full written description of the scope and goals of this study. Participation was voluntary. The experts gave their consent in the course of completing Round 1 or 2 of this Delphi survey.

\section{Consent for publication}

Not applicable.

\section{Competing interests}

The authors declare that they have no competing interests.

\section{Author details}

'Medignition Inc. Medical Research Consultants, Verena Conzett-Strasse 9, 8004 Zurich, Switzerland. ${ }^{2}$ Center for Rheumatology and Bone Disease, Bellariastrasse 38, 8038 Zurich, Switzerland. ${ }^{3}$ Division of Rheumatology, University Hospital Zurich, Gloriastrasse 25, 8091 Zurich, Switzerland. ${ }^{4}$ Department of Rheumatology and Clinical Immunology/Allergology, University Hospital Bern, Freiburgstrasse 18, 3010 Bern, Switzerland.

${ }^{5}$ University of Zurich, Rämistrasse 71, 8006 Zurich, Switzerland.

Received: 25 March 2019 Accepted: 10 October 2019

Published online: 12 November 2019

\section{References}

1. Centre for Metabolic Bone Diseases UoS, UK. Fracture Risk Assessment Tool [Available from: https://www.sheffield.ac.uk/FRAX/tool.aspx? country=14.

2. Middleton RG, Shabani F, Uzoigwe CE, Shoaib A, Mogsith M, Venkatesan M. FRAX and the assessment of the risk of developing a fragility fracture. J Bone Joint Surg Br. 2012;94(10):1313-20.

3. Najafi DA, Dahlberg LE, Hansson EE. A combination of clinical balance measures and FRAX (R) to improve identification of high-risk fallers. BMC Geriatr. 2016;16.

4. Fink A, Kosecoff J, Chassin M, Brook RH. Consensus methods - characteristics and guidelines for use. Am J Public Health. 1984;74(9):979-83.

5. Moll MA, Bachmann LM, Joeris A, Goldhahn J, Blauth M. Parameters pointing at an increased risk for contralateral hip fractures: systematic review. Geriatr Orthop Surg. 2016;7(1):45-61.

6. SurveyMonkey. SurveyMonkey [Available from: https://www. surveymonkey.com/.

7. Brunner F, Lienhardt SB, Kissling RO, Bachmann LM, Weber U. Diagnostic criteria and follow-up parameters in complex regional pain syndrome type I--a Delphi survey. Eur J Pain. 2008;12(1):48-52.

8. ClinRisk-Ltd. QFracture [Available from: http://www.qfracture.org/index.php.

9. Marques A, Ferreira RJO, Santos E, Loza E, Carmona L, da Silva JAP. The accuracy of osteoporotic fracture risk prediction tools: a systematic review and meta-analysis. Ann Rheum Dis. 2015;74(11):1958-67.

10. Sambrook PN, Cameron ID, Chen JS, Cumming RG, Lord SR, March LM, et al. Influence of fall related factors and bone strength on fracture risk in the frail elderly. Osteoporosis Int. 2007;18(5):603-10.

11. Albrand G, Munoz F, Sornay-Rendu E, Duroeuf F, Delmas PD. Independent predictors of all osteoporosis related fractures in healthy postmenopausal women. The ofely study. Osteoporosis Int. 2002;13:S28-S.

12. Lunt M, O'Neill TW, Felsenberg D, Reeve J, Kanis JA, Cooper C, et al. Characteristics of a prevalent vertebral deformity predict subsequent vertebral fracture: results from the European prospective osteoporosis study (EPOS). Bone. 2003;33(4):505-13.
13. Delmas PD, Genant HK, Crans GG, Stock JL, Wong M, Siris E, et al. Severity of prevalent vertebral fractures and the risk of subsequent vertebral and nonvertebral fractures: results from the MORE trial. Bone. 2003;33(4):522-32.

14. Johansson H, Kanis JA, Oden A, McCloskey E. Mild morphometric vertebral fractures predict vertebral fractures but not nonvertebral fractures. Osteoporosis Int. 2013;24:S310-S1.

15. Humphrey-Murto S, Varpio L, Wood TJ, Gonsalves C, Ufholz LA, Mascioli K, et al. The use of the Delphi and other consensus group methods in medical education research: a review. Acad Med. 2017;92(10):1491-8.

\section{Publisher's Note}

Springer Nature remains neutral with regard to jurisdictional claims in published maps and institutional affiliations.
Ready to submit your research? Choose BMC and benefit from:

- fast, convenient online submission

- thorough peer review by experienced researchers in your field

- rapid publication on acceptance

- support for research data, including large and complex data types

- gold Open Access which fosters wider collaboration and increased citations

- maximum visibility for your research: over $100 \mathrm{M}$ website views per year

At $\mathrm{BMC}$, research is always in progress.

Learn more biomedcentral.com/submissions 